\section{Capitalismo e vigilância digital na sociedade democrática}

\section{Capitalism and digital surveillance in democratic society}

ZUBOFF, Shoshana. (2019), The Age of Surveillance Capitalism: the fight for a human future at the new frontier of power. Nova York, Public Affairs.

\section{Andrei Koerner}

http://orcid.org/0000-0002-4354-9963

Professor de Ciência Política na Unicamp, DiretorPresidente do Cedec e Pesquisador do GPDH-IEA/ USP e do INCT/Ineu, Campinas - SP, Brasil. E-mail: andreiko@uol.com.br

DOI: $10.1590 / 3610514 / 2020$

Esta resenha estava em preparação quando começou a pandemia do Corona Vírus. Em meio a medidas epidemiológicas e embates políticos, cogitam-se usos de tecnologias digitais para controlar o vírus. De imediato, passou-se a monitorar processos fisiológicos e comportamentos, e as Big Techs se propuseram a criar novas tecnologias "para o bem". Porém, o fato é que elas e os governos já dispóem de amplo espectro de técnicas para a observação, registro e incitação dos indivíduos. No futuro próximo haverá difusão e intensificação de seu uso, embora, nos últimos anos, elas têm sido vistas com preocupação crescente. Assim, a discussão sobre as formas, usos, efeitos e implicaçóes sociais das tecnologias ganha maior relevo e urgência.

O capitalismo de vigilância é uma mutação do capitalismo da informação, que nos coloca diante de um desafio civilizacional. As Big Techs - seguidas por outras firmas, laboratórios e governos - usam tecnologias da informação e comunicação (TIC) para expropriar a experiência humana, que se torna matéria-prima processada e mercantilizada como dados comportamentais. $\mathrm{O}$ usuário cede gratuitamente as suas informaçôes ao concordar com termos de uso, utilizar serviços gratuitos ou, simplesmente, circular em espaços onde as máquinas estão presentes.
A condição para a emergência do capitalismo de vigilância foi a expansão das tecnologias digitais na vida cotidiana, dado o sucesso do modelo de personalizaçâo dos produtos da Apple no início dos anos 2000. No terço final do século XX, estavam criadas as condiçóes para uma terceira modernidade, voltada à realização dos valores e expectativas dos indivíduos. O neoliberalismo contraria essas potencialidades, porque maximiza as necessidades dos indivíduos, mas bloqueia suas possibilidades de supri-las, tornando-os vulneráveis às promessas e riscos do mundo digital. As autoridades não controlaram a concentração das empresas, não limitaram as técnicas comportamentais nem criaram restriçóes legais para os termos de uso.

Outras circunstâncias foram ocasionais: o estouro da bolha da internet em 2000 e os ataques terroristas do 11 de setembro. A primeira provocou a retração dos investimentos nas Startups, o que levou a Google a explorar comercialmente os dados dos usuários de seus serviços. Para se prevenir contra novos ataques, as autoridades norte-americanas tornaram-se ávidas por programas de monitoramento dos usuários da internet, financiaram e se associaram às empresas de tecnologia. Por sua vez, a Google passava a vender dados a empresas de outros setores, criando um mercado de comportamentos futuros. Assim, instaurou-se uma nova divisão do aprendizado entre os que controlam os meios de extração da mais-valia comportamental e os seus destinatários.

Ao se generalizar na sociedade e se aprofundar na vida cotidiana, o capitalismo de vigilância capturou e desviou o efeito democratizador da Internet que abrira a todos o acesso à informação. Ele passou a elaborar instrumentos para modificar e conformar os nossos comportamentos. Alguns exemplos são surpreendentes: gadgets que monitoram processos fisiológicos, bonecas que extraem dados das crianças, dispositivos "vestíveis" ou implantáveis no corpo. O Pokémon Go foi uma experiência para levar as pessoas a agirem no mundo real como se estivessem no mundo virtual, provendo lucros reais para as empresas que o contrataram. Assistentes pessoais registram comportamentos, interaçóes e ambientes dos usuários, para antecipar suas ações e realizar vendas. A computação dos afetos, que já é instalada em crachás e veículos de empresas, traça o perfil de 
personalidade do usuário e captura em tempo real suas emoçóes reveladas pela voz, por exemplo, para atuar sobre seus processos pré-conscientes. Fábricas automatizadas, integradas em redes e com sistemas de aprendizado adaptam o seu funcionamento, criando relaçóes nas quais os humanos se tornam acessórios monitorados por elas.

Um novo poder instrumental estaria em vias de conformar um Big Other, um projeto de sociedade planejada que reduziria as pessoas a uma condição animal, simples organismos que se comportam. Os atuais utopistas são dotados de conhecimento, poder e recursos para, como Alex Pentland, do MIT, produzir máquinas que nos condicionam a criar relaçóes harmônicas e pacíficas, realizando os projetos de B.F. Skinner. Configurar-se-ia um espaço social sem qualquer possibilidade de recuo ou isolamento dos indivíduos face aos instrumentos tecnológicos, o que seria um desafio à natureza humana que, como todas as criaturas, necessita de "santuários" para recompor suas energias e processar os seus desejos de futuro.

A tese central é que o capitalismo de vigilância configura um regime, ou ordem econômica, contrário às bases da civilização liberal. A instalação em curso do poder instrumental afetaria nossos sentimentos e formas de vida, por corroer a confiança nos outros, quebrar reciprocidades e esvaziar a nossa capacidade de criar compromissos e de construir perspectivas compartilhadas de futuro, eliminando nossa autonomia ou livre vontade. Ele é distinto do totalitarismo, pois é operado por empresas, adota meios de modificação soft dos comportamentos, e sua finalidade é o lucro. Ele se afasta do capitalismo de mercado porque pretende a informação total e a certeza sobre comportamentos e processos sociais, quebra as reciprocidades entre empresas, empregados e consumidores, e projeta um novo coletivismo com exclusão social, exploração do trabalho precário e indiferença radical em relação à sociedade. Seria um golpe a partir de cima, dirigido contra o mercado, que impôs unilateralmente o controle do conhecimento e declarou sua própria legitimidade. Uma tirania que se alimentaria das pessoas e que implicaria a obliteração da política.

Seus efeitos colocariam uma questão ontológica, pois a violação do santuário e a programação dos comportamentos póem em xeque o que é mais precioso na natureza humana: a vontade de vontade, a santidade do indivíduo, os vínculos de intimidade, a sociabilidade que nos vincula por promessas, as confianças que alimentamos. Eles seriam nefastos para a democracia, pois nos tornaríamos uma espécie de colmeia ou rebanho dirigido pelas empresas de tecnologia digital e pastoreado pelos sacerdotes dos saberes da informática. Coloca-se, então, o problema ético de recuperar o sentido de ultraje, a indignação e a ação coletiva contra o que se passa. Deve-se formular declaraçôes sintéticas de direitos que proclamem o futuro digital como um lugar humano, para limitar o capitalismo digital e defender a divisão do aprendizado na sociedade. Deve-se não só controlar o capitalismo de vigilância, mas, numa espécie de New Deal, recusá-lo e construir um novo regime que subordine o poder das tecnologias digitais e recrie relaçôes de confiança e reciprocidade numa sociedade democrática.

Esse é um resumo da tese sustentada por Shoshana Zuboff, professora emérita da Business School da Universidade de Harvard, no livro aqui resenhado, publicado há pouco mais de um ano. A tese ressoa e sintetiza muitos alertas que destacam os efeitos negativos e os riscos sociais postos pela generalização de algoritmos que usam Big Data e inteligência artificial.

O livro foi escrito para se tornar um best-seller e seu impacto foi grande no mercado editorial e no espaço público. Foi logo aclamado como uma obra de referência sobre a economia da informação, equivalente ao Capital no século XXI, de Piketty, ou mesmo ao Capital. A página da autora ${ }^{1}$ enumera indicações do livro para prêmios e listas das melhores obras do ano. Ele serviu de base para documentários, filmes e obras de ficção, e foi publicado em vinte países, dentre os quais o Brasil, pela editora Intrínseca, no final de 2020.

Em cerca de 700 páginas, ela combina a análise do regime emergente com um manifesto de alerta para os seus riscos. Ela traz a história da economia da informação e sua mutação em capitalismo de vigilância, apresenta e faz um balanço das tecnologias existentes, da legislação e suas falhas, das ações e omissóes dos governantes, e ainda apresenta os planos dos dirigentes das principais empresas de tecnologia para reorganizar a sociedade. Sob o aspecto do alcance 
da narrativa, o livro é bastante relevante, pois traz informaçōes úteis, principalmente para não iniciados.

Em seu propósito didático e moral, a autora fez recapitulaçôes e desenvolvimentos desnecessários, que tornaram o longo texto por vezes tedioso. Mas, por vezes, tem-se a sensaçấo da leitura de um thriller. Conhecemos o viláo e seus propósitos, mas o enredo nos reserva revelaçóes surpreendentes sobre seus engenhos e artes, impressionantes e assustadores. A experiência foi potencializada pela minha condição de iniciante no campo, com limitado conhecimento de trabalhos sobre tecnologias de informação e comunicação e sociedade.

O livro foi trabalhado com os alunos da disciplina Política e Direito II do curso de Ciências Sociais da Unicamp, no segundo semestre de 2019, aos quais agradeço por sua participação e, de certo modo, coautoria desta resenha. Inicialmente, considerouse a privacidade como questâo individual, definida como liberdade de escolha para aceitar os termos de uso dos provedores dos produtos ou serviços. Nossas discussóes voltaram-se à busca de regras para o controle do uso dos dados dos usuários. Ao longo da leitura, o foco se ampliou para os problemas sociais e políticos postos pela invasão das tecnologias no cotidiano e a sua extrapolação para o mundo real.

O livro produziu seu efeito retórico, ao despertar surpresa, indignação e sensação de urgência, mas também de impotência, em muitos ou quase todos nós. Mas logo vieram a primeiro plano as críticas à construção do argumento e ao que parecia inicialmente a principal qualidade do livro: um trabalho com um enfoque liberal e democrático, bem informado e documentado, que mostra as tendências e critica os riscos das tecnologias digitais. Aparece aqui o grande problema: a autora nomeia o fenômeno como capitalismo de vigilância, mas não discute temas e questôes postos na ordem do dia por outros críticos. A tese ocupa o espaço da crítica com conceituação inadequada e pode produzir um efeito de desconhecimento, que conjuga seu efeito retórico e o bloqueio à reflexão e elaboração conceitual sobre o presente.

Para preparar a presente resenha, fez-se busca na Internet de publicaçôes sobre a obra, e foram localizados cerca de noventa itens, que compreendem notas em jornais e magazines, entrevistas, bem como ediçôes especiais, resenhas e artigos acadêmicos que citam ou debatem as teses do livro. ${ }^{2}$ Após rápida leitura, uma vintena foi selecionada para análise, trabalho que proporcionou uma incursão na área de tecnologia e sociedade, em particular em dois campos: a economia da informação e estudos sobre vigilância.

A maioria das publicaçóes elogiou a oportunidade e qualidade da obra. Há as inevitáveis cogitaçōes na fronteira da ficção científica sobre os riscos para a humanidade postos por máquinas superinteligentes sem controle, ou por aqueles que as controlam. Criticouse o exagero desses riscos, por ter a autora assumido o ponto de vista dos empresários e engenheiros de software que tendem a superestimar as suas próprias criaçóes. A capacidade de prediçáo e direçấo dos comportamentos dos gadgets seria limitada, pois eles produzem scripts lineares e fracos, sáo desenhados para modificar comportamentos em situaçóes específicas, e sua operação depende de condiçôes contextuais controladas (Maly, 2019).

No campo da economia, o ponto de vista da indústria se expressou com críticas à omissão da obra aos benefícios, em termos de produtividade, proporcionados pelos produtos e serviços das TIC. $\mathrm{O}$ problema da vigilância não seria relevante, pois só se usam metadados, e o objetivo da elaboração de perfis individuais seria a melhoria dos serviços. A regulação seria contraproducente, por frear a inovação, criar custos para os usuários e ser inócua, pois a tecnologia suplantaria qualquer controle. A privacidade seria um direito subjetivo mercantilizável pelo seu titular, cuja liberdade de escolha se exerceria ao contratar os termos de uso. Apenas a competição entre as empresas protegerá a privacidade, pois elas ofereceráo termos mais vantajosos para os clientes, que poderão escolher modelos por design e vender seus dados. Enfim, reafirma-se o caráter neutro e progressivo da técnica, pois com ela se criaria a possibilidade de superar todos os problemas (Batkins, 2019; "Is Google an evil genius?”, 2019; Thornhill, 2019).

Outras críticas focam na perspectiva da obra, cujas unidades seriam o Estado, as firmas e os consumidores, e no seu objetivo de restaurar uma relaçấo virtuosa entre eles. Morozov (2019) aponta as debilidades do livro em relação à dimensão econômica do capitalismo de vigilância. Dado que o interesse da autora está 
nas relaçóes entre a firma e o consumidor, as firmas seriam impelidas por imperativo tecnológico para a extração da mais-valia dos comportamentos. Para Morozov, a causa não seria um imperativo técnico, pois a vigilância seria apenas efeito local de uma causa global. As firmas de tecnologia adotam sua estratégia de coleta de dados porque são guiadas pela necessidade de assegurar sua lucratividade de longo prazo. Fazem isso por meio da superação de concorrentes, crescimento rápido, externalização dos custos e apoio do poder político. Extraem dados e modificam comportamentos quando relevantes nesse contexto. Só há um regime, o capitalismo, e a disputa não seria prioritariamente por dados, mas por poder de mercado, lógica de expansão de toda firma.

Para o crítico, o ponto central não seria a vigilância nem a modificação de comportamentos (esta, aliás, inevitável), pois, mesmo que os dados fossem extraídos numa relação de reciprocidade "virtuosa" entre firmas e usuários, sua lógica não deixaria de ser capitalista. Seria inadequado conceituar a extraçáo de dados como expropriação ou usurpação da experiência, pois dados não são escassos nem de uso exclusivo. Ao não discutir as diferenças e relaçóes entre experiência e trabalho, a obra desloca o foco das relações de produção e da força de trabalho necessária para a mercantilização de dados obtidos (quase) gratuitamente na Internet. Por não discutir o antagonismo de classes e focar na intimidade do consumidor ameaçado, a obra seria uma regressão no conhecimento da economia digital. Enfim, ela só considera alternativas de proteção dos indivíduos e não de coletividades e desconsidera as lutas por direitos socioeconômicos, o uso irrestrito das infraestruturas, a criptografia de dados, a solidariedade e não o lucro.

Outros autores afirmam que os imperativos de acumulação do capitalismo da informação explicam as estratégias adotadas pelas Big Techs, cujas peculiaridades seriam decorrência da lógica de fronteira da expansão dessa nova forma de capitalismo. O capitalismo de vigilância viola a privacidade e invade os domínios de existência porque essa é a dinâmica de acumulação do seu setor dominante, o capital de plataforma, que necessita extrair dados para os seus negócios. Torna-se central a discussão sobre a plataforma, o que implica passar do enfoque das firmas de tecnologia para esse modelo de negócio que se disseminou e se tornou dominante na economia e no Estado. Uma estrutura cuja lógica subordina outras instituiçóes e determina os termos em que indivíduos, organizaçóes e governos interagem. São intermediários que geram novos mercados, e são produtores que extraem, analisam e mercantilizam dados; para tanto, precisam assegurar seu acesso a dados cada vez mais extensos diversificados. Assim, a vigilância para extração de dados é inerente à sua lógica e não será controlada ou eliminada por restriçôes legais ou regulaçôes. A tendência não seria um poder instrumentário global, mas batalhas por monetização e controle. As empresas viriam a criar ambientes fechados, com maior respeito à privacidade, mas com identificação constante dos usuários (Murakami Wood e Monahan, 2019; Sadowski, 2019; Srnicek, 2017; Malmgren, 2019; Manokha, 2018). ${ }^{3}$

No campo dos estudos sobre vigilância, a autora foi criticada por não elaborar apropriadamente a noçáo de vigilância. ${ }^{4}$ Sua noção seria de senso comum e se esquiva de discussóes a respeito dos efeitos da vigilância sobre o corpo, normatividade e ordem. Seria preciso discutir a lógica militar das empresas de tecnologia, e como ela se propaga na sociedade de várias formas. Por exemplo, na linguagem cotidiana, nas estratégias de denegação das Big Techs, na lavagem cerebral dos seus empregados, nos elementos viciantes dos gadgets (Ball, 2019).

Estar-se-ia num momento pós-disciplinar, da vigilância automatizada que opera ambientalmente e não supóe a internalização do olhar pelo sujeito. O simbólico é deslocado pelo atual, torna-se real o olhar onisciente que não necessita um vigiado consciente. A vigilância tem caráter pós-representacional. Ela é operacional, porque trabalha para a regulação dos efeitos e atua ao invés de indicar ou alertar e, por isso, é preciso vigiar o tempo todo. Ela fecha o espaço do julgamento humano e da política, e o seu ponto final será a automatizaçáo do julgamento, para superar as limitações do humano. Seu perigo não é que seja aperfeiçoada, mas que ajamos como se ela pudesse ser (Andrejevic, 2019). Mas parece que coexistem muitos "cercados" (enclosures) digitais e não um hiperpanóptico. Esses ambientes são controlados por diversos atores, e podem ser conectados, concentrados e 
comunicados conforme as suas projeçóes, necessidades e usos desejados, sem diferenciação entre as esferas do mercado e da segurança estatal (Frow, 2019, p. 23).

Zuboff teria minimizado os vínculos das Big Techs com o governo norte-americano, ao construílos como aliança eventual na Guerra contra o Terror e complacência dos legisladores. Há uma série de pontos não tematizados, tais como os vínculos entre as empresas e o aparato de inteligência, o complexo industrial-militar e o capital financeiro; o seu papel instrumental para a preservação ou renovação da hegemonia norte-americana no sistema internacional; e o fato de que os usos da vigilância sobre os trabalhadores, minorias e marginalizados são historicamente constitutivos da sociedade capitalista (Khan, 2019; Starr, 2019; Evangelista, 2019).

Outro aspecto da discussão diz respeito à mediação da vida pelo digital, a produção de valor e a onipresença da vigilância. Os conservadores indagam: onde está o dano? O consumidor parece satisfeito, entusiasmado, entretido com o mundo que as tecnologias lhes oferecem... Zuboff e seus críticos marxistas veem a mediação como mais-valia comportamental extraída da experiência humana, como dados produzidos por uma espécie de trabalho não reconhecido como tal, realizado pelos usuários (para além daquele realizado pelos que trabalham nos empregos precários das Big Techs).

Os conceitos de experiência humana, dados, trabalho, comportamento e matéria-prima precisam ser repensados. Se o imperativo da acumulação explica a lógica das empresas, não explica a relação dos usuários/trabalhadores com as tecnologias digitais. Se a lógica da vigilância indica os riscos da tecnologia para a democracia e os direitos humanos, não se entende a entrega voluntária das pessoas a esses riscos. Se mecanismos tecnológicos procuram modificar os nossos comportamentos, não se vê qual é a sua novidade em relação a outras mídias e à indústria cultural. Pensar a base da produção de valor e o alvo das atividades de vigilância supóe colocar as perguntas: o que é extraído? Do que "isso" se extrai? O ponto torna-se o da mediação das relações sociais pelo digital e a constituição de objetividades e subjetividades nos entrelaçamentos entre o virtual e o real.
O que é a experiência humana que é transformada em dados? A transformaçâo "desincorpora” pulsaçôes e processos biológicos, "desindividualiza" sensaçóes, gestos, vínculos; descontextualiza açóes, eventos e interaçóes; recolhe traços, restos, pistas e os homogeneíza e mercantiliza. Forma uma representação do agente, um "divíduo" (Rouvroy e Berns, 2013), um agregado, um "composto" que será o alvo dos impulsos, incitaçôes e mensagens "personalizadas" que se lhe apresentam de forma anônima, despercebida ou não autorizada. Por sua vez, os agentes, os data-selves (Lupton, 2019), respondem, reagem, calculam e recriam a si mesmos, as suas interações, a sua ação coletiva, as suas relaçóes com as máquinas e com o mundo.

O que parece novo é que as tecnologias digitais permitem incitaçóes que se exercem em tempo real, de forma intensa e disseminada sobre cada um e sobre a multiplicidade. São técnicas autocorretivas, com informações imediatas e baseadas em dados massivos sobre populações, categorizaçóes sociais e o próprio "divíduo". Elas têm como campo de operação a articulação entre o vital, o afetivo e o volitivo do agente, e atuam na formação das representações e emoções do sujeito que vive, fala, deseja, age e constitui a si próprio e os seus objetos. Sobre as multiplicidades, elas incidem sobre os impulsos, interações, fluxos, de modo antecipatório, com instrumentos de gestão ambiental e capacidade de intervenção imediata.

Em conclusão, o livro informa e nomeia uma espécie de "cristalização" das formas assumidas pela conjunção entre tecnologias digitais e capitalismo na atualidade. Suas ilustrações sobre as técnicas de inteligência artificial aplicadas ao cotidiano servem para dramatizar os temores sobre os efeitos agregados das mudanças tecnológicas dos últimos quarenta anos. O livro é exemplar ao colocar uma questão civilizacional, mas a autora o vê com os olhos dos liberais norte-americanos, nostálgicos do pós-New Deal, e a obra tem importantes problemas no que diz respeito à sua abordagem, aparato conceitual e tese central.

Sugerimos, enfim, pensar os problemas da tecnologia na atualidade do ponto de vista dos efeitos da ampliação e intensificação da mediação digital no cotidiano. Elas produzem uma normatividade que se exerce além das normas jurídicas e aquém das açóes 
e interações conscientes, visando antecipá-las, o que leva a indagar sobre suas implicaçóes para o estado de direito e as maneiras pelas quais a imaginação constitucional deverá trabalhar para contê-las e redirecioná-las.

\section{Notas}

1 https://shoshanazuboff.com/book/, acessada em 30/03/2020.

2 Alguns deles são anteriores a 2019, pois se referem aos artigos em que a autora publicou sua tese central (Zuboff, 2014; 2015).

3 Discute-se se os dados são mercadoria fictícia, trabalho não mercantilizado, matéria-prima ou capital; se as plataformas são as empresas, o modelo de negócios, uma fração ou uma estrutura ou relação objetiva de forças; e se as tecnologias digitais estão em continuidade, inflexão ou ruptura com a lógica do capitalismo industrial.

4 Destaca-se o número especial da revista Surveillance \& Society, 17, 1/2, 2019, sobre Platform Surveillance.

\section{Referências}

ANDREJEVIC, Mark. (2019), "Automating Surveillance”. Surveillance \& Society, 17, 1/2: 7-13. DOI: https://doi. org/10.24908/ss.v17i1/2.12930.

BALL, Kirstie. (2019), "Review of Zuboff's 'The Age of Surveillance Capitalism: The Fight for a Human Future at the New Frontier of Power"'. Surveillance \& Society, 17, 1/2: 252-256. DOI: https://doi.org/10.24908/ ss.v17i1/2.13126.

BATKINS, Sam. (2019), “The Tech Giants Are Out to Get You”. Regulation, 52, Summer: 52-53.

EVANGELISTA, Rafael. (2018), “Review of Zuboff's 'The Age of Surveillance Capitalism: The Fight for a Human Future at the New Frontier of Power'". Surveillance \& Society 17, 1/2: 246-251. DOI: https:// doi.org/10.24908/ss.v17i1/2.13132

FROW, John. (2019), “Cookie”. Cultural Studies Review, 25, 2: 208-210. DOI: https:// doi.org/10.5130/csr. v25i2.6899

"Is Google an evil genius?" (2019), The Economist, 19 jan. (Schumpeter): 75. Disponível em: <https://www.economist. com/business/2019/01/19/is-google-an-evil-genius>.

KHAN, Aasim. (2019), “Book Review”. Social Change, 49, 4: 735-38. DOI: https://doi. org/10.1177/0049085719872928.
LUPTON, Deborah. (2019), Data Selves. Cambridge, Polity.

MALY, Ico. (2019), “The age of surveillance capitalism (Shoshana Zuboff), 2019. Disponível em: <https://www. diggitmagazine.com/book-reviews/age-surveillancecapitalism>.

MALMGREN, Evan. (2019), "Resisting 'Big Other': What Will It Take to Defeat Surveillance Capitalism?”. New Labor Forum, 28, 3: 42-50. DOI: https://doi. org/10.1177/1095796019864097.

MANOKHA, Ivan. (2018), "Le scandale Cambridge Analytica contextualisé: le capital de plateforme, la surveillance et les données comme nouvelle 'marchandise fictive”. Cultures \& Conflits, 109, printemps. DOI: https://doi.org/10.4000/conflits.19779.

MOROZOV Evgeny. (2019), “Capitalism's New Clothes. Shoshana Zuboff's new book on 'surveillance capitalism' emphasizes the former at the expense of the later". The Baffler, 4 fev. Disponível em: <https://thebaffler.com/ latest/capitalisms-new-clothes-morozov>

MURAKAMI WOOD, David \& MONAHAN, Torin. (2019), "Editorial: Platform Surveillance". Surveillance \& Society, 17, 1/2: 1-6. DOI: https://doi.org/10.24908/ ss.v17i1/2.13237.

ROUVROY, Antoinette \& BERNS, Thomas. (2013), "Gouvernementalité algorithmique et perspectives d'émancipation”. Réseaux, 1, 177: 163-196. DOI: https://doi.org/10.3917/res.177.0163.

SADOWSKI, Jathan. (2019), "When data is capital: Datafication, accumulation, and extraction". Big Data \& Society, jan./jun.: 1-12. DOI: https://doi. org/10.1177/2053951718820549.

STARR, Paul. (2019), "How Neoliberal Policy Shaped the Internet - and What to Do About It Now". The American Prospect, 2 out. (Money, Politics and Power). Disponível em: <https://prospect.org/power/how-neoliberal-policyshaped-internet-surveillance-monopoly/>.

THORNHILL, John. (2019), "We Must Train the Capitalist Algorithm Ourselves". Financial Times, 11 fev. (Opinion). Disponível em: <https://www.ft.com/ content/2db2cdb4-2dda-11e9-8744-e7016697f225>.

ZUBOFF, Shoshana. (2014), "A Digital Declaration”. Frankfurter Allgemeine Zeitung, 15 set. (Debatten). Disponível em: <https://www.faz.net/aktuell/feuilleton/ debatten/the-digital-debate/shoshan-zuboff-on-big-dataas-surveillance-capitalism-13152525.html>.

ZUBOFF, Shoshana. (2015). “Big Other: Surveillance Capitalism and the Prospects of an Information Civilization”. Journal of Information Technology, 30, 1: 75-89. DOI: https://doi.org/10.1057/jit.2015.5. 